\title{
Case Report of Novel LAMB2 Gene Mutation in Palestinian Infant with Pierson (Microcoria-Congenital Nephrosis) Syndrome
}

\author{
Zaid $\mathrm{M}^{*}$, Bahar $\mathrm{S}^{2}$ and Alawneh $\mathrm{M}^{1}$ \\ ${ }^{1}$ Department of Paediatrics, An-Najah National University Hospital, Nablus, Palestine \\ ${ }^{2}$ Department of Paediatric Nephrology, An-Najah National University Hospital, Nablus, Palestine
}

${ }^{*}$ Corresponding author: Zaid M, Department of Paediatrics, An-Najah National University Hospital, Nablus, Palestine, Tel: 00972568210002,E-mail: dr.mahdiz@yahoo.com

Citation: Zaid M, Bahar S, Alawneh M (2019) Case Report of Novel LAMB2 Gene Mutation in Palestinian Infant with Pierson (Microcoria-Congenital Nephrosis) Syndrome J Nephrol Kidney Dis 1(1): 103. doi: $10.15744 / 2767-9225.1 .103$

Received Date: March 17, 2019 Accepted Date: April 27, 2020 Published Date: April 29, 2020

\begin{abstract}
Laminin $\beta 2$ (LAMB2) gene mutation typically causes a rare autosomal recessive inherited disorder called Pierson syndrome (PS) that present in the neonatal period and progressively affecting renal and ocular functions in the form of congenital nephrotic syndrome (CNS) combined with bilateral microcoria.

We report the first Palestinian case of Pierson syndrome with proven causative unique LAMB2 gene mutation that is not documented before. She presented with congenital nephrotic syndrome and having bilateral microcoria. Patient died at age of 52 days with acute pulmonary oedema and septic shock.
\end{abstract}

Keywords: LAMB2; Congenital Nephrotic Syndrome; Microcoria; Pierson Syndrome; Novel Mutation

\section{Introduction}

Pierson syndrome (Microcoria-congenital nephrosis) is a rare inherited disorder characterized by congenital nephrotic syndrome that rapidly progressing to end stage renal failure within first 3 months of life. It can be accompanied by extra-renal manifestations, such as microcoria and neurological abnormalities. It is a rare condition originally described in 1963 [1,2]. The genetic background was identified in 2004 as mutations that affect the LAMB2 gene on chromosome 3p21. Since 2004, less than 50 cases of Pierson syndrome have been described [3]. We here report on a patient with neonatal LAMB2 gene analysis revealed an unreported homozygous.

\section{Methodology}

We describe a case of neonatal Pierson syndrome from Palestine which confirmed by LAMB2 gene analysis that revealed compound homozygous mutation at position p.Arg550Ter (R550X) in exon 13 of LAMB2 gene.

\section{Case Presentation}

This patient was a 19 days old girl with the gestational age of 37 weeks presented with generalized oedema and renal dysfunction, who was admitted to NICU of An-Najah National University Hospital. The baby girl for 1st degree cousins was born at another hospital by caesarean section with history of severe oligohydramnios. The weight of the placenta was unknown. She weighed 2600 $\mathrm{g}$ and appeared vigorous, with spontaneous respirations. Apgar scores were 8 and 9 at 1 and 5 minutes, respectively. The rest of the physical examination findings were normal.

Eight days post-delivery, baby had abrupt onset of progressive lower limb oedema with eyes puffiness. Her parents with low socioeconomic state not took medical advice till one week later when oedema exacerbated and become generalized, led to sought medical advice and hospitalization of patient at other hospital. Laboratory investigations revealed a severe nephrotic range proteinuria with acute renal failure, total plasma protein $2.8 \mathrm{~g} / \mathrm{dL}$ (reference range $4.6-7.0 \mathrm{~g} / \mathrm{dl}$ ), albumin $0.9 \mathrm{~g} / \mathrm{dL}$ (reference range $2.6-3.6 \mathrm{~g} / \mathrm{dL}$ ) and plasma creatinine 4 $\mathrm{mg} / \mathrm{dL}$ (reference range $0.17-0.88 \mathrm{mg} / \mathrm{dL}$ ), in addition to electrolytes imbalance in form of hyperkalaemia and hyponatremia (potassium 6.8mmol/L, sodium $105 \mathrm{mmol} / \mathrm{L}$ ). Lipid profile were elevated (Triglyceride $365 \mathrm{mg} / \mathrm{dL}$, Cholesterol $299 \mathrm{mg} / \mathrm{dL}$ ). 
On admission, baby was 19 days of age, weighted 3120 gm. Furthermore, the examination showed generalized oedema, distended abdomen, blood pressure 110/52 $\mathrm{mmHg}$ and other vital signs were within normal ranges.

Laboratory tests showed hemoglobin $12.03 \mathrm{~g} / \mathrm{dL}$, white blood cells $13.7 \mathrm{~K} / \mathrm{uL}$, platelets $552 \mathrm{k} / \mathrm{uL}$, BUN $27.7 \mathrm{mg} / \mathrm{dL}$, serum creatinine $3.6 \mathrm{mg} / \mathrm{dL}$, total serum protein $3.63 \mathrm{mmol} / \mathrm{L}$, albumins $1.5 \mathrm{~g} / \mathrm{dL}$, potassium $3.63 \mathrm{mmol} / \mathrm{L}$, sodium $115 \mathrm{mmol} / \mathrm{L}$, calcium $7 \mathrm{mg} / \mathrm{dL}$. Urine analysis revealed proteinuria $(+3)$ and spot urine for protein/creatinine ratio was $152 \mathrm{mg} / \mathrm{mg}$, while the thyroid function was normal. Serology for TORCH and HBsAg were negative. Kidney ultrasound showed normal sized hyperechoic kidneys, right kidney $5 \mathrm{~cm}$ in bipolar length while the left kidney measured $5.5 \mathrm{~cm}$, with loss of corticomedullary differentiation. Doppler sonography revealed normal renal vasculature with good renal blood flow.

Therapy was started with albumin infusion, furosemide, antibiotics, low salt intake and high protein diet with regular follow up by a paediatric nephrologist.

After few days of hospitalization, she developed more worsening of renal dysfunction with serum creatinine level $4.6 \mathrm{mg} / \mathrm{dL}$ and getting more oedematous, so patient started daily peritoneal dialysis. Few days later, ophthalmic examination despite using mydriatic eye drops showed bilateral papillary constriction $(0.9 \mathrm{~mm} /$ normal $\geq 2 \mathrm{~mm})$ (Figure 1$)$.

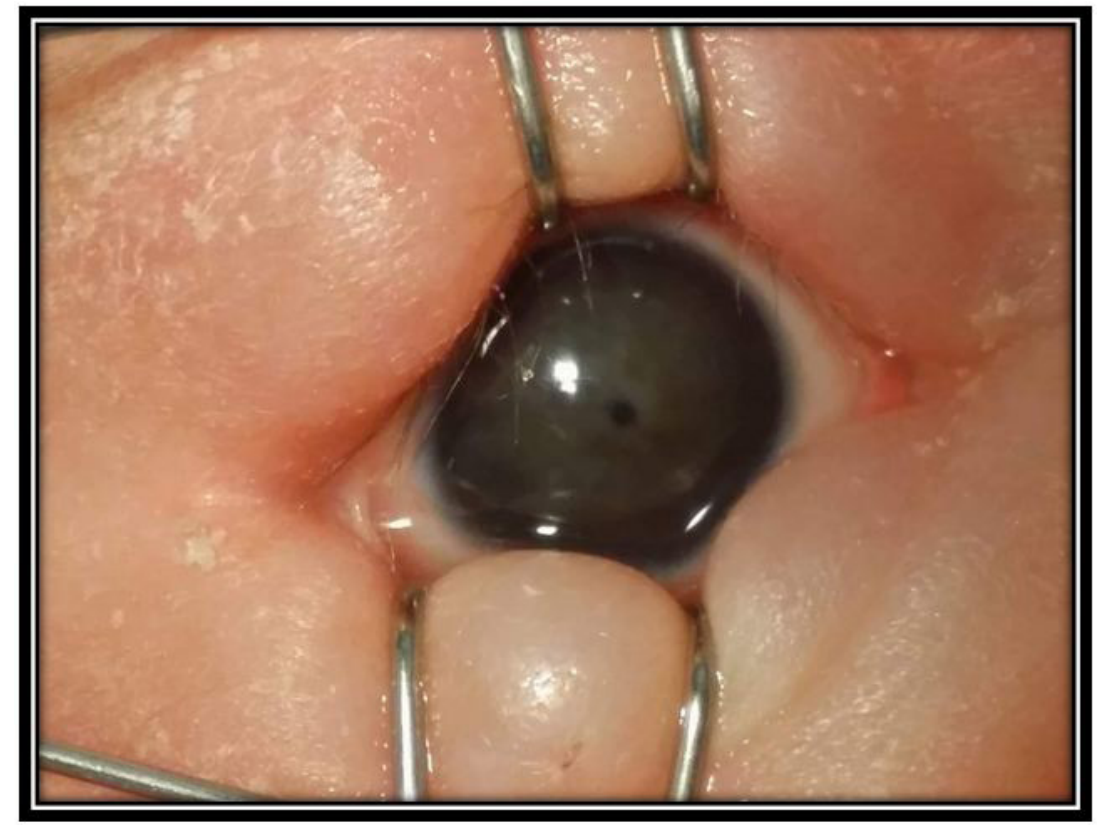

Figure 1: Clinical finding of Bilateral Microcoria, consistent with Pierson Syndrome

Based on this clinical scenario with history of oligohydramnios, progressive generalized oedema and nephrotic range proteinuria with presence of microcoria; Pierson syndrome was suspected. Genetic testing of LAMB2 gene revealed a novel homozygous mutation sp.Arg550Ter (R550X) in exon 13 of LAMB2 gene which is not documented before.

After 32 days in neonatal ICU with daily peritoneal dialysis and Albumin infusion, baby developed urosepsis with Acinetobacter baumannii and Klebsiella pneumoniae growth organisms and died with severe pulmonary oedema and septic shock.

\section{Discussion}

Pierson syndrome (Microcoria-congenital nephrosis) is a rare disorder characterized by congenital nephrotic syndrome rapidly progressing to end stage renal failure accompanied by extra-renal manifestations, such as microcoria (fixed extreme narrowing of the pupils) and neurological abnormalities [4]. Pierson syndrome caused by rare an autosomal recessive mutation in LAMB2 gene locus on the chromosome 3p21 which encoding laminin beta-2 [5]. Laminins represent a key extracellular macromolecular glycoprotein component of basement membranes. Each laminin is a heterotrimer consisting of $\alpha, \beta$ and $\gamma$ chains, which exist in five $(\alpha 1-\alpha 5)$, four $(\beta 1-\beta 4)$, and three $\left(\gamma 1-\gamma^{3}\right)$ isoforms [6]. These three short arms of the cross-shaped laminin molecule joint together forming the network nodes that interfering with collagen IV, integrins, cellular domains, and proteoglycans such as dystroglycan [7-9]. Therefore, this complex matrix plays important roles in tissue morphogenesis and homeostasis by regulating cell adhesion, migration, differentiation and proliferation. The structural and biological variety of the laminins has started to be explained by the identification of laminin defects and gene targeting in acquired or inherited human diseases [7].

Laminin-521 trimer $(\alpha 5 \beta 2 \gamma 1)$ that contains a $\beta 2$-chain is a major component in mature glomerular basement membrane (GBM), ocular structures, and the neuromuscular system. Mutations in LAMB2 gene preventing LM-521 synthesis and/or secretion explaining these organs involvement with Pierson syndrome [3]. Disruption in the GBM's laminin-521 network integrity by 
LAMB2 mutation, a key protein of cell adhesion, interfere with glomerular filtration barrier cause nephrotic range proteinuria and sclerotic changes of the glomeruli, this rapidly leads to end stage renal failure within first 3 months of life (10-12).

Extra-renal associated abnormalities, including in the ocular and neuronal defects also an important finding in PS but not overall PS patients. Human laminin $\beta 2$ deficiency lead to ocular maldevelopment of structures of the anterior eye segment; particularly the intraocular muscles and lens with characteristic bilateral ciliary and pupillary muscles dysgenesis causing nonreactive microcoria [4,12-14]. Other ocular abnormalities of the lens, iris and retina had been reported, but they are less common than microcoria as a little residual function of LAMB2 can be sufficient for normal development of these parts of orbit [15].

Neurodevelopmental symptoms reported in some patients with LAMB2 mutations, which become obvious after the first month of life, including muscular hypotonia, muscle weakness, intellectual disability, hearing defect and speech delay. These neurological deficits and developmental delay not have specific mutation subtype, but reported with complete deficiency of laminin $\beta 2$ [10,16].

Pierson syndrome has poor prognosis and most patients rapidly deteriorating towards renal failure within the first 3 months of life. Currently, symptomatic management is only available by parenteral albumin infusion and dialysis. Kidney transplantation can restore renal function as long term option [17]. Alternatively, as Pierson syndrome (PS) caused by LAMB2 mutation that disrupting in the GBM's laminin-521 (LM-521) network integrity, so studies for replacement therapy by human LM-521 (hLM521) protein injection in patient with PS showed positive outcome by preventing proteinuria and renal worsening [18,19]. Ophthalmic management by surgical widening of pupillary opening and follow up of other sequels as cataract, glaucoma and retinal detachments should be considered [14].

\section{Conclusion}

Any infant suspecting congenital nephrotic syndrome within first 3 months of life, should undergo ophthalmologic examination to rule out ocular abnormalities like microcoria that consistent with a Pierson syndrome diagnosis. On the contrary, any patient presenting with microcoria should undergo renal function screening to exclude Pierson syndrome $[2,4]$.

\section{References}

1. Pierson M, Cordier J, Hervouuet F, Rauber G (1963) An unusual congenital and familial congenital malformative combination involving the eye and kidney. J Genet Hum 12: 184-213.

2. Zenker M, Aigner T, Wendler O, Tralau T, Müntefering H, et al. (2004) Human laminin $\beta 2$ deficiency causes congenital nephrosis with mesangial sclerosis and distinct eye abnormalities. Hum Mol Genet 13: 2625-32.

3. Matejas V, Hinkes B, Alkandari F, Al-Gazali L, Annexstad E, et al. (2010) Mutations in the human laminin $\beta 2$ (LAMB2) gene and the associated phenotypic spectrum. Hum Mutat 31: 992-1002.

4. Zenker, Martin, Tralau T, Lennert T, Pitz S, et al. (2004) Congenital nephrosis, mesangial sclerosis, and distinct eye abnormalities with microcoria: an autosomal recessive syndrome. Am J Med Genet A 130: 138-45.

5. Machuca E, Benoit G, Nevo F, Tête MJ, Gribouval O (2010) Genotype-phenotype correlations in non-Finnish congenital nephrotic syndrome. J Am Soc Nephrol 21: 1209-17.

6. Kino J, Tsukaguchi H, Kimata T, Nguyen HT, Nakano Y, et al. (2017) Nephron development and extrarenal features in a child with congenital nephrotic syndrome caused by null LAMB2 mutations. BMC Nephrol 18: 220.

7. Aumailley M, Smyth N (1998) The role of laminins in basement membrane function. J Anat 193: 1-21.

8. Hohenester E, Yurchenco PD (2013) Laminins in basement membrane assembly. Cell Adh Migr 7: 56-63.

9. Hamill KJ, Kligys K, Hopkinson SB, Jones JC (2009) Laminin deposition in the extracellular matrix: a complex picture emerges. J Cell Sci 122: 4409-17.

10. Jarad G, Miner JH (2009) Update on the glomerular filtration barrier. Curr Opin Nephrol Hypertens 18: 226-32.

11. Miner JH (2011) Organogenesis of the kidney glomerulus: Focus on the glomerular basement membrane. Organogenesis 7: 75-82.

12. Hasselbacher K, Wiggins RC, Matejas V, Hinkes BG, Mucha B, et al. (2006) Recessive missense mutations in LAMB2 expand the clinical spectrum of LAMB2associated disorders. Kidney Int 70: 1008-12.

13. Cochat P, Zenker M (2011) Pierson syndrome, Michel Pierson (Le syndrome de Pierson, Michel Pierson. Arch de pédiatrie) Pediatr Arch 18: 1127-9.

14. Bredrup C, Matejas V, Barrow M, Bláhová K, Bockenhauer D, et al. (2008) Ophthalmological aspects of Pierson syndrome. Am J Ophthalmol 146: 602- 11.

15. Kagan M, Cohen AH, Matejas V, Vlangos C, Zenker M (2008) A milder variant of Pierson syndrome. Pediatr Nephrol 23: 323-7.

16. Wuhl E, Kogan J, Zurowska A, Matejas V, Vandevoorde RG, et al. (2007) Neurodevelopmental deficits in Pierson (microcoria-congenital nephrosis) syndrome. Am J Med Genet A 143: 311-9.

17. Guler S, Cimen S, Acott P, Whelan K, Molinari M (2017) Kidney transplantation in a child with Pierson syndrome. Pediatr Transplant 21: e13076.

18. Lin MH, Miller JB, Kikkawa Y, Suleiman HY, Tryggvason K, et al. (2018) Laminin-521 protein therapy for glomerular basement membrane and podocyte abnormalities in a model of pierson syndrome. J Am Soc Nephrol 29: 1426-36.

19. Tryggvason, Karl R, Sergey (2013) Recombinant laminin-521, United States Patent No 8415156. 


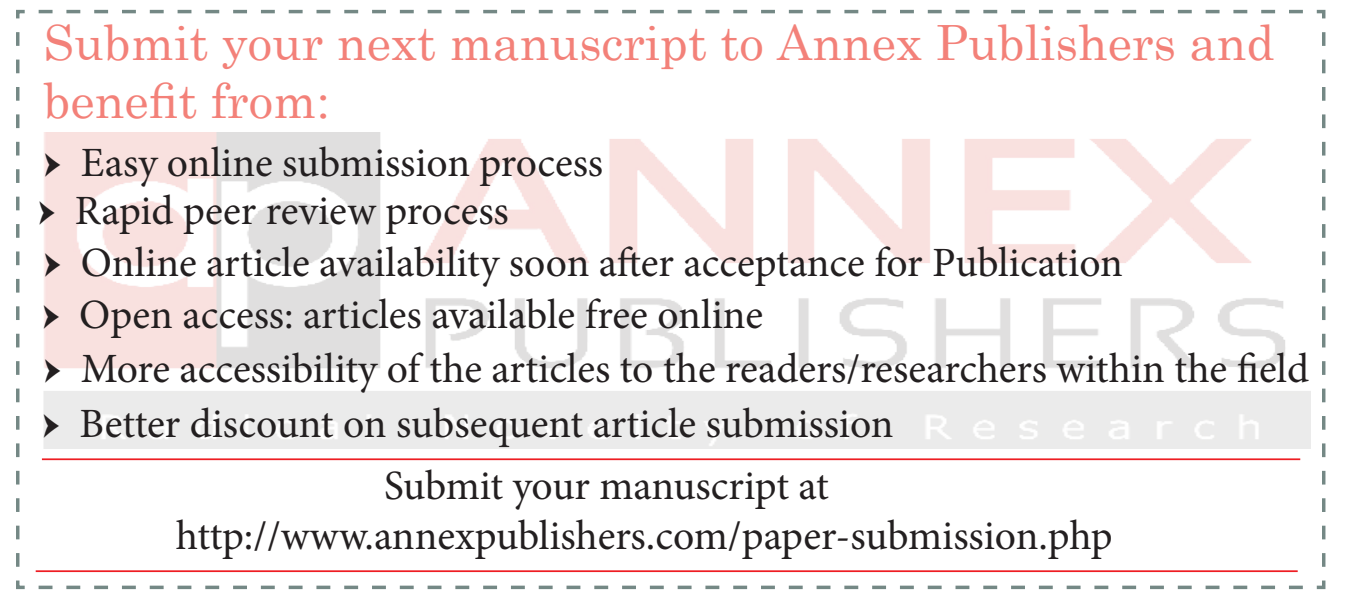

